\title{
Episiotomy use among vaginal deliveries and the association with anal sphincter injury: a population-based retrospective cohort study
}

\author{
Giulia M. Muraca PhD MPH, Shiliang Liu MB PhD, Yasser Sabr MD MHSc, Sarka Lisonkova MD PhD, \\ Amanda Skoll MD, Rollin Brant PhD, Geoffrey W. Cundiff MD, Olof Stephansson MD PhD, Neda Razaz PhD MPH, \\ K.S. Joseph MD PhD
}

— Cite as: CMAJ 2019 October 21;191:E1149-58. doi: 10.1503/cmaj.190366

\begin{abstract}
BACKGROUND: The rate of obstetric anal sphincter injury has increased in recent years, particularly among operative vaginal deliveries. We sought to characterize temporal trends in episiotomy use and to quantify the association between episiotomy and obstetric anal sphincter injury.
\end{abstract}

METHODS: Using a population-based retrospective cohort study design of hospital data from 2004 to 2017, we studied all vaginal deliveries of singleton infants at term gestation in Canada (excluding Quebec). Rates of obstetric anal sphincter injury were contrasted between women who had an episiotomy and those who did not. Logbinomial regression was used to estimate the association between episi- otomy and obstetric anal sphincter injury among women with spontaneous and operative vaginal deliveries after controlling for confounders.

RESULTS: The study population included 2570847 deliveries. Episiotomy use declined significantly among operative vaginal deliveries $(53.1 \%$ in 2004 to $43.2 \%$ in $2017, p<0.0001$ ) and spontaneous vaginal deliveries (13.5\% in 2004 to $6.5 \%$ in 2017, $p<0.0001$ ). Episiotomy was associated with higher rates of obstetric anal sphincter injury among spontaneous vaginal deliveries (4.8 with episiotomy v. $2.4 \%$ without; adjusted rate ratio [RR] 2.06, 95\% confidence interval $[\mathrm{Cl}] 2.00-2.11$ ) and this association remained after stratification by parity and obstetric history. In con- trast, episiotomy was associated with lower rates of obstetric anal sphincter injury among forceps deliveries in nulliparous women (adjusted RR 0.63, 95\% $\mathrm{Cl}$ 0.61-0.66), and women with vaginal birth after cesarean (adjusted RR 0.71, $95 \% \mathrm{Cl} 0.60-0.85$ ), but not among parous women without a previous cesarean (adjusted RR 1.16, 95\% Cl 1.00-1.34).

INTERPRETATION: Episiotomy use has declined in Canada for all vaginal deliveries. The protective association between episiotomy and obstetric anal sphincter injury among women who gave birth by operative vaginal delivery (especially forceps) warrants reconsideration of clinical practice among nulliparous women and those attempting vaginal birth after cesarean.

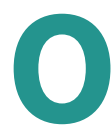

bstetric anal sphincter injury, defined as third- and fourth-degree perineal laceration, is a maternal morbidity that may occur during vaginal delivery and lead to short- and long-term complications including perineal pain, infection, diminished sexual function, incontinence, abscess formation and rectovaginal fistulae. ${ }^{1}$ Obstetric anal sphincter injury is the most common cause of fecal incontinence among women ${ }^{1,2}$ and, while primary surgical repair after delivery can reduce pelvic floor dysfunction, the mean rate of anal incontinence reported after primary repair is $39 \% .^{2}$ Over the last 15 years, the rate of obstetric anal sphincter injury has increased by up to $15 \%$ in several industrialized countries, including Canada, ${ }^{3}$ Sweden, ${ }^{4,5}$ Norway, ${ }^{6}$ the United Kingdom ${ }^{7,8}$ and Australia. ${ }^{9}$ Possible explanations for the increase in such injuries include the rise in maternal age at first birth, which is linked to higher risk of perineal tears, and improved case detection and recording of obstetric injuries. ${ }^{7}$

The risk of obstetric anal sphincter injury differs by type of delivery. In 2015, 3.1\% of Canadian women had anal sphincter injury after a spontaneous vaginal delivery. ${ }^{10}$ However, among operative vaginal deliveries, the risk was substantially higher; $18.4 \%$ of Canadian women had anal sphincter injury after operative vaginal delivery in 2017. ${ }^{11,12}$ From 2015 to 2017, operative 
vaginal delivery accounted for $10 \%-13 \%$ of deliveries in Canada, the UK and Australia. ${ }^{13-15}$ The rate of operative vaginal delivery is notably lower in the United States, at $3.1 \%$ in $2015,{ }^{16}$ where efforts to increase the use of operative delivery as a strategy to reduce cesarean delivery rates are underway. ${ }^{17}$ Thus, research aimed at reducing the high and increasing rate of obstetric anal sphincter injury among operative vaginal deliveries is essential to minimize the number of women affected.

Factors associated with obstetric anal sphincter injury among operative vaginal deliveries include nulliparity, macrosomia and prolonged second stage of labour..$^{1,2,18-20}$ Episiotomy is a potentially modifiable risk factor, although previous studies on the association between episiotomy use in operative vaginal delivery and obstetric anal sphincter injury have shown inconsistent results. Indications for episiotomy include nulliparity, shoulder dystocia, breech delivery, fetal macrosomia, prolonged second stage of labour, previous obstetric anal sphincter injury and the need for rapid delivery (e.g., with fetal distress or precipitous labour). ${ }^{21} \mathrm{~A}$ recent Cochrane review ${ }^{22}$ examining episiotomy among vaginal deliveries concluded that routine episiotomy use among spontaneous vaginal deliveries results in higher rates of anal sphincter injury and that there is insufficient evidence on the effects of episiotomy on anal sphincter injury among operative vaginal deliveries. Similarly, the World Health Organization 2018 guideline on intrapartum care emphasizes that the role of episiotomy in operative vaginal delivery remains to be established. ${ }^{23}$

The objectives of this study were 2-fold: to describe the temporal trends in episiotomy use in Canada, stratified by parity, obstetric history and mode of vaginal delivery, and also to quantify the associations between episiotomy and obstetric anal sphincter injury within each of these strata.

\section{Methods}

We carried out a population-based retrospective cohort study on all hospital deliveries in Canada, excluding Quebec, using data obtained from the Discharge Abstract Database of the Canadian Institute for Health Information. ${ }^{24}$ Trained health records personnel abstracted information in this database from medical records, using standardized definitions. These data included details on maternal characteristics, medical history, labour and delivery, neonatal outcomes and details of diagnoses and interventions or procedures. Diagnoses and procedures in the database represent notations in the medical chart made by physicians and were coded using the enhanced Canadian version of the International Statistical Classification of Diseases and Related Health Problems, 10th revision (ICD-10-CA) ${ }^{25}$ and the Canadian Classification of Interventions. ${ }^{26}$ Data accuracy was ensured through routine quality assurance checks. Previous validation studies have confirmed the accuracy of perinatal information in the database. ${ }^{27,28}$ Indicators of maternal morbidity, such as obstetric anal sphincter injury, had a high sensitivity and specificity (sensitivity for third- and fourth-degree perineal lacerations was $97.1 \%$ and $94.7 \%$, respectively, and specificity for both diagnoses was $99.9 \%){ }^{27}$

Our study included all vaginal deliveries between 37 and 41 weeks' gestation that resulted in a singleton live birth between April 2004 and March 2018 (fiscal years 2004 to 2017). We excluded deliveries by cesarean, in breech presentation and those with uncertain information on mode of delivery or birth weight. Information on parity was not systematically collected in some provinces and therefore we examined temporal trends in episiotomy and the association between episiotomy and obstetric anal sphincter injury in the overall cohort and also within a restricted cohort of deliveries that excluded $22 \%$ of the study population without information on parity.

We stratified operative vaginal deliveries by instrument applied (forceps, vacuum or sequential application of each instrument) and grouped them into 3 categories based on pelvic station: outlet, low-pelvic and midpelvic. ${ }^{21}$ Episiotomy included both midline and mediolateral, as information on the type of episiotomy was not included in our data source. However, mediolateral episiotomy accounts for more than $90 \%$ of the episiotomies that occur in Canada. ${ }^{29,30}$ The primary outcome was obstetric anal sphincter injury, which included both third- and fourthdegree perineal lacerations.

\section{Statistical analysis}

In the restricted cohort of deliveries with information on parity, we categorized women by parity and obstetric history into 3 strata: nulliparous, parous without a previous cesarean delivery, and vaginal birth after cesarean delivery. Within these strata, we assessed temporal trends in episiotomy use by mode of vaginal delivery (i.e., spontaneous and operative), operative instrument and pelvic station using the Cochran-Armitage test for linear trend in proportions by year and by comparing rates in 2017 with those in 2004.

We estimated adjusted rate ratios (RRs) and 95\% confidence intervals (Cls) using log-binomial regression models to quantify the associations between episiotomy and obstetric anal sphincter injury. We used stratified analyses to quantify the effects of instruments (forceps, vacuum, sequential instrumentation) and the pelvic station at which the operative vaginal delivery was attempted, while adjusting for potential confounders; namely, maternal age, labour induction, prolonged second stage of labour, epidural anesthesia, infant birth weight, province and year of delivery. We based the determination of potential confounders on clinical understanding, the literature and epidemiologic principles. Codes used for the inclusion and exclusion criteria, confounders and outcomes are listed in Appendix 1, Table S1, available at www.cmaj.ca/lookup/suppl/doi:10.1503/ cmaj.190366/-/DC1. We quantified absolute effects by calculating adjusted rate differences and the adjusted number needed to treat (NNT).

We conducted 5 sensitivity analyses to examine issues related to the degree of obstetric anal sphincter injury laceration (thirdv. fourth-degree); confounding by indication (by restricting the analysis to deliveries with a diagnosis of fetal distress in an effort to compare women with a comparable indication for episiotomy); obstetric history (by stratifying parous women into women with 1 previous vaginal delivery and 1 previous cesarean delivery); provider experience and case mix using institutional delivery volume (low, medium or high) as a proxy measure; and the 
Table 1: Numbers and rates of women with an episiotomy by mode of delivery and by maternal and infant

characteristics, among all term singleton vaginal deliveries, Canada, 2004-2017*

\begin{tabular}{|c|c|c|c|}
\hline \multirow[b]{2}{*}{ Characteristic } & \multirow[b]{2}{*}{ No. deliveries } & \multicolumn{2}{|c|}{ With episiotomy } \\
\hline & & No. & Rate, \% \\
\hline All vaginal deliveries & 2570847 & 374071 & 14.6 \\
\hline Spontaneous & 2205056 & 206184 & 9.4 \\
\hline Operative & 365791 & 167877 & 45.9 \\
\hline Forceps & 89145 & 58284 & 65.4 \\
\hline Vacuum & 258058 & 97057 & 37.6 \\
\hline Sequential & 18588 & 12546 & 67.5 \\
\hline \multicolumn{4}{|l|}{ Maternal age, yr } \\
\hline$<20$ & 114419 & 18588 & 16.2 \\
\hline $20-24$ & 410675 & 59219 & 14.4 \\
\hline $25-29$ & 779305 & 118272 & 15.2 \\
\hline $30-34$ & 829780 & 119524 & 14.4 \\
\hline $35-39$ & 369479 & 49388 & 13.4 \\
\hline $40-44$ & 64577 & 8698 & 13.5 \\
\hline$\geq 45$ & 2610 & 380 & 14.6 \\
\hline \multicolumn{4}{|l|}{ Parity } \\
\hline 1 & 877676 & 221647 & 25.3 \\
\hline $2-3$ & 709375 & 68555 & 9.7 \\
\hline$\geq 4$ & 393222 & 15603 & 4.0 \\
\hline \multicolumn{4}{|l|}{ Induction } \\
\hline Yes & 589819 & 94016 & 15.9 \\
\hline No & 1981028 & 280055 & 14.1 \\
\hline \multicolumn{4}{|l|}{ Epidural } \\
\hline Yes & 1096568 & 193756 & 17.7 \\
\hline No & 1474279 & 180315 & 12.2 \\
\hline \multicolumn{4}{|c|}{ Prolonged second stage } \\
\hline Yes & 130426 & 49978 & 38.3 \\
\hline No & 2440421 & 324093 & 13.3 \\
\hline \multicolumn{4}{|l|}{ Fetal distress } \\
\hline Yes & 591902 & 147875 & 25.0 \\
\hline No & 1978945 & 226196 & 11.4 \\
\hline \multicolumn{4}{|l|}{ Birth weight, g } \\
\hline$<2500$ & 40151 & 5365 & 13.4 \\
\hline 2500-2999 & 369207 & 53437 & 14.5 \\
\hline $3000-3499$ & 1027742 & 149274 & 14.5 \\
\hline 3500-3999 & 840322 & 122293 & 14.6 \\
\hline $4000-4499$ & 253484 & 37504 & 14.8 \\
\hline$\geq 4500$ & 39941 & 6198 & 15.5 \\
\hline
\end{tabular}

${ }^{*} P$ value for all bivariable comparisons $<0.0001$; derived from $X^{2}$ test for difference in proportion of maternal or infant characteristics among deliveries with and without episiotomy in each respective parity and obstetric history group. robustness of the results to unmeasured confounding using E-value methodology. ${ }^{31}$ The latter analysis estimates the minimum strength of association that an unmeasured confounder would need to have with both episiotomy and obstetric anal sphincter injury, conditional on the confounders in the regression model, to explain the observed association fully. ${ }^{31}$

The a priori level of statistical significance was set at a 2-sided $p$ value of 0.05 for all analyses. We conducted all analyses using SAS version 9.4 for Windows (SAS Institute Inc., Cary, NC).

\section{Ethics approval}

Ethics approval for the study was obtained from the Clinical Research Ethics Board at the University of British Columbia (H14-02746).

\section{Results}

The study included 2570847 singleton, term deliveries, of which $1998618(78 \%)$ had information on parity (Figure 1). The rate of episiotomy among spontaneous vaginal deliveries and operative vaginal deliveries was $9.4 \%$ and $45.9 \%$, respectively (Table 1 ). The episiotomy rate among spontaneous vaginal deliveries was $16.8 \%$ in nulliparous women, $5.6 \%$ in parous women with no history of cesarean delivery, and $10.6 \%$ in women with vaginal birth after cesarean. The episiotomy rate in operative vaginal deliveries was $52.5 \%, 24.9 \%$ and $41.7 \%$, respectively, in these 3 groups (Table 2).

Among operative vaginal deliveries, episiotomy use varied depending on operative instrument, with a rate of $65.4 \%$ with forceps, $37.6 \%$ with vacuum and $67.5 \%$ with sequential instruments. Within each instrument category, these rates were highest in nulliparous women and lowest in parous women with no history of cesarean delivery (Table 2). Among nulliparous women and parous women without a previous cesarean delivery, episiotomy was more commonly performed in older women and women with larger infants. Women who had an episiotomy were more likely to have had an induction, epidural anesthesia, a prolonged second stage of labour and fetal distress (Table 2, and Appendix 1, Table S2). Significant differences in the distribution of maternal, infant and obstetric characteristics are presented using standardized differences in Appendix 1, Table S3.

\section{Temporal trends in the episiotomy rate}

Large, significant declines in episiotomy rates occurred between 2004 and 2017 among women having a spontaneous vaginal delivery (percent change $-51.9 \%, p<0.0001$ ) and among women having an operative vaginal delivery $(-18.6 \%, p<0.0001$; Appendix 1, Tables S4-S7). These trends remained after we stratified women into the 3 parity groups (Figure 2A). Episiotomy use among operative vaginal deliveries declined from $58.9 \%$ in 2004 to $50.4 \%$ in 2017 in nulliparous women, from $30.7 \%$ to $22.9 \%$ among parous women without a previous cesarean delivery, and from $46.8 \%$ to $41.6 \%$ among women with a vaginal birth after cesarean. Episiotomy rates varied by province, especially among forceps and vacuum deliveries (Appendix 2, Figure S1, available at www.cmaj.ca/lookup/suppl/doi:10.1503/cmaj.190366/-/DC1). 


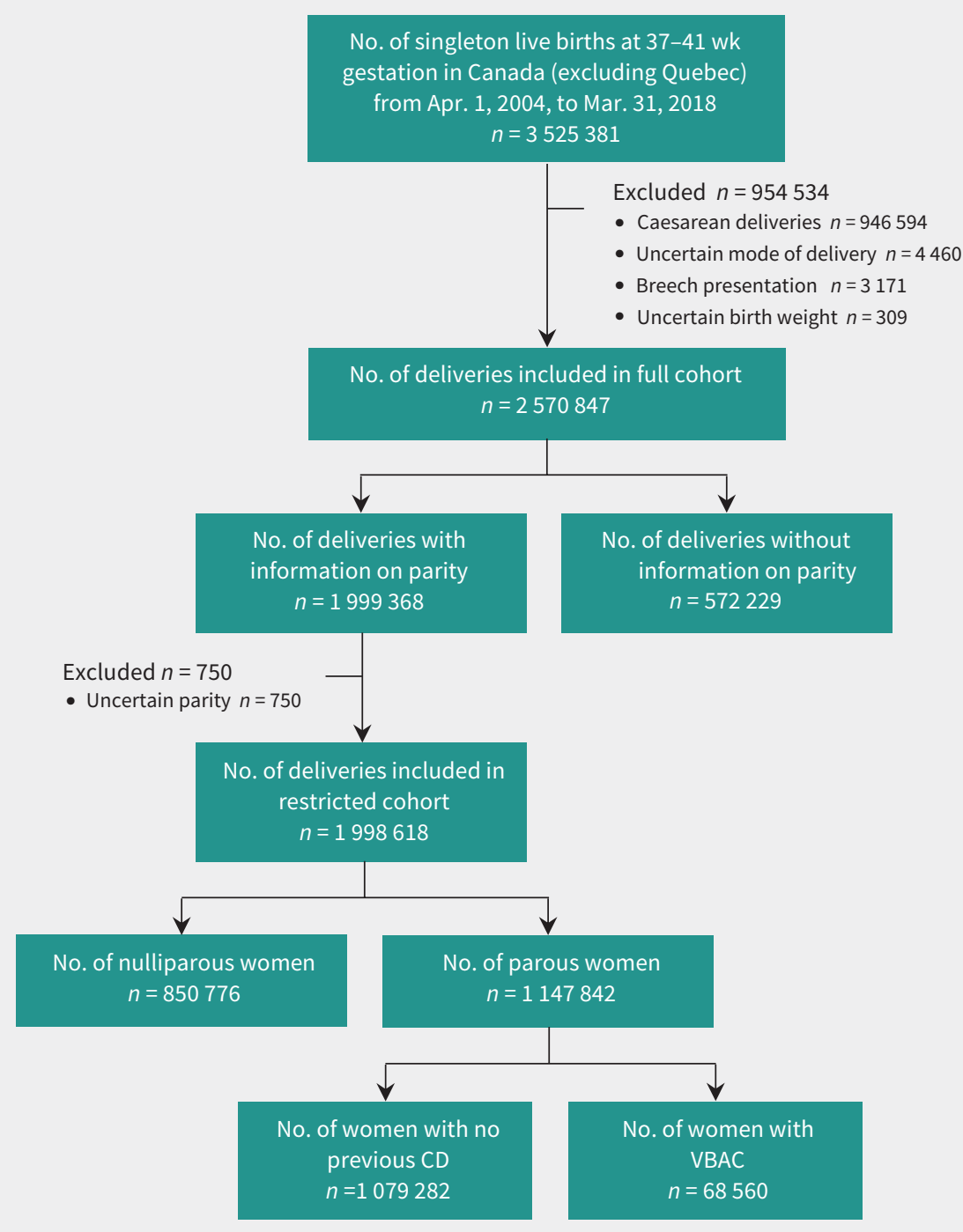

Figure 1: Derivation of study cohort. The sum of individual exclusions may exceed the total at each point as a result of deliveries being excluded for multiple reasons. Note: $\mathrm{CD}=$ cesarean delivery, $\mathrm{VBAC}=$ vaginal birth after cesarean .

\section{Rates of obstetric anal sphincter injury and association with episiotomy}

The rate of obstetric anal sphincter injury among all vaginal deliveries was $4.3 \% ; 7.7 \%$ in nulliparous women, $1.5 \%$ in parous women without a previous cesarean delivery, and $6.7 \%$ in women with a vaginal birth after cesarean. The rate of obstetric anal sphincter injury increased significantly over the study period in all 3 groups (Appendix 3, Figure S2, available at www.cmaj.ca/lookup/ suppl/doi:10.1503/cmaj.190366/-/DC1 and Appendix 4, Figure S3, available at www.cmaj.ca/lookup/suppl/doi:10.1503/cmaj $.190366 /-/ D C 1)$. The greatest temporal increase in the rate of obstetric anal sphincter injury was among forceps deliveries without an episiotomy and deliveries with sequential instruments in all groups (Appendix 1, Table S8).
Among women in the full cohort with a spontaneous vaginal delivery, episiotomy was associated with increased rates of obstetric anal sphincter injury (adjusted RR $2.06,95 \% \mathrm{Cl} 2.00$ 2.11; Table 3). In nulliparous women and women with a vaginal birth after cesarean, this association was weaker (Figure 3), while in parous women without a previous cesarean, it was stronger (adjusted RR 2.55, 95\% Cl 2.42-2.69).

In the full cohort, there was a protective association between episiotomy and obstetric anal sphincter injury among forceps deliveries (adjusted RR $0.74,95 \% \mathrm{Cl} 0.71-0.77$ ), and this association was stronger in nulliparous women (adjusted RR 0.63, 95\% $\mathrm{Cl}$ 0.61-0.66; Table 4). In contrast, among parous women without a previous cesarean delivery, episiotomy was associated with a nonsignificant increased risk of obstetric anal sphincter injury 
Table 2: Numbers and rates of women with an episiotomy by mode of delivery and by maternal and infant characteristics, among all term singleton vaginal deliveries with information on parity, Canada, 2004-2017*

\begin{tabular}{|c|c|c|c|c|c|c|c|c|c|}
\hline \multirow[b]{3}{*}{ Characteristic } & \multicolumn{3}{|c|}{ Nulliparous } & \multicolumn{3}{|c|}{ Parous, no previous CD } & \multicolumn{3}{|c|}{ VBAC } \\
\hline & \multirow[b]{2}{*}{ No. deliveries } & \multicolumn{2}{|c|}{ With episiotomy } & \multirow[b]{2}{*}{ No. deliveries } & \multicolumn{2}{|c|}{ With episiotomy } & \multirow[b]{2}{*}{ No. deliveries } & \multicolumn{2}{|c|}{ With episiotomy } \\
\hline & & No. & Rate \% & & No. & Rate \% & & No. & Rate \% \\
\hline All vaginal deliveries & 850776 & 217252 & 25.5 & 1079282 & 72976 & 6.8 & 68560 & 11240 & 16.4 \\
\hline Spontaneous & 641809 & 107564 & 16.8 & 1016324 & 57281 & 5.6 & 55724 & 5891 & 10.6 \\
\hline \multicolumn{10}{|l|}{ Operative } \\
\hline Forceps & 55403 & 38185 & 68.9 & 7906 & 3845 & 48.6 & 3194 & 1963 & 61.5 \\
\hline Vacuum & 141779 & 63069 & 44.5 & 53007 & 10887 & 20.5 & 9065 & 3023 & 33.3 \\
\hline Sequential & 11785 & 8434 & 71.6 & 2045 & 963 & 47.1 & 577 & 363 & 62.9 \\
\hline \multicolumn{10}{|l|}{ Maternal age, yr } \\
\hline$<20$ & 74434 & 14270 & 19.2 & 13750 & 440 & 3.2 & 499 & 83 & 16.6 \\
\hline $20-24$ & 178828 & 40491 & 22.6 & 129787 & 5126 & 4.0 & 6165 & 923 & 15.0 \\
\hline $25-29$ & 288212 & 75198 & 26.1 & 303427 & 17561 & 5.8 & 17784 & 2843 & 16.0 \\
\hline $30-34$ & 228937 & 63407 & 27.7 & 392350 & 29248 & 7.5 & 26654 & 4497 & 16.9 \\
\hline $35-39$ & 69782 & 20583 & 29.5 & 201141 & 16968 & 8.4 & 14751 & 2490 & 16.9 \\
\hline $40-44$ & 10191 & 3164 & 31.1 & 37267 & 3479 & 9.3 & 2594 & 389 & 15.0 \\
\hline$\geq 45$ & 392 & 139 & 35.5 & 1560 & 154 & 9.9 & 113 & 15 & 13.3 \\
\hline \multicolumn{10}{|l|}{ Parity } \\
\hline 1 & 0 & 0 & 0.0 & 656968 & 59046 & 9.0 & 37035 & 8820 & 23.8 \\
\hline $2-3$ & 0 & 0 & 0.0 & 357759 & 13130 & 3.7 & 25152 & 2284 & 9.1 \\
\hline$\geq 4$ & 0 & 0 & 0.0 & 64555 & 800 & 1.2 & 6373 & 136 & 2.1 \\
\hline \multicolumn{10}{|l|}{ Induction } \\
\hline Yes & 213603 & 57151 & 26.8 & 246704 & 17712 & 7.2 & 12234 & 1816 & 14.8 \\
\hline No & 637173 & 160101 & 25.1 & 832578 & 55264 & 6.6 & 56326 & 9424 & 16.7 \\
\hline \multicolumn{10}{|l|}{ Epidural } \\
\hline Yes & 475661 & 125166 & 26.3 & 410859 & 31809 & 7.7 & 34152 & 6281 & 18.4 \\
\hline No & 375115 & 92086 & 24.6 & 668423 & 41167 & 6.2 & 34408 & 4959 & 14.4 \\
\hline \multicolumn{10}{|c|}{ Prolonged second stage } \\
\hline Yes & 69449 & 30014 & 43.2 & 13098 & 2568 & 19.6 & 4190 & 1387 & 33.1 \\
\hline No & 781327 & 187238 & 24.0 & 1066184 & 70408 & 6.6 & 64370 & 9853 & 15.3 \\
\hline \multicolumn{10}{|l|}{ Fetal distress, yes } \\
\hline Yes & 262927 & 91783 & 34.9 & 189225 & 20659 & 10.9 & 19652 & 4898 & 24.9 \\
\hline No & 587849 & 125469 & 21.3 & 890057 & 52317 & 5.9 & 48908 & 6342 & 13.0 \\
\hline \multicolumn{10}{|l|}{ Birth weight, g } \\
\hline$<2500$ & 17497 & 3571 & 20.4 & 14095 & 719 & 5.1 & 1018 & 160 & 15.7 \\
\hline $2500-2499$ & 147985 & 34302 & 23.2 & 135708 & 8019 & 5.9 & 9740 & 1580 & 16.2 \\
\hline $3000-3499$ & 365026 & 90424 & 24.8 & 410690 & 26184 & 6.4 & 27044 & 4371 & 16.2 \\
\hline 3500-3999 & 252678 & 68037 & 26.9 & 371720 & 25831 & 7.0 & 22726 & 3767 & 16.6 \\
\hline $4000-4499$ & 60461 & 18438 & 30.5 & 125098 & 10055 & 8.0 & 6845 & 1163 & 17.0 \\
\hline$\geq 4500$ & 7129 & 2480 & 34.8 & 21971 & 2168 & 9.9 & 1187 & 199 & 16.8 \\
\hline
\end{tabular}

Note: $C D=$ cesarean delivery, $\mathrm{VBAC}=$ vaginal birth after cesarean.

${ }^{*} P$ value for all bivariable comparisons $<0.0001$; derived from $X^{2}$ test for difference in proportion of maternal or infant characteristics among deliveries with and without episiotomy in each respective parity and obstetric history group. 


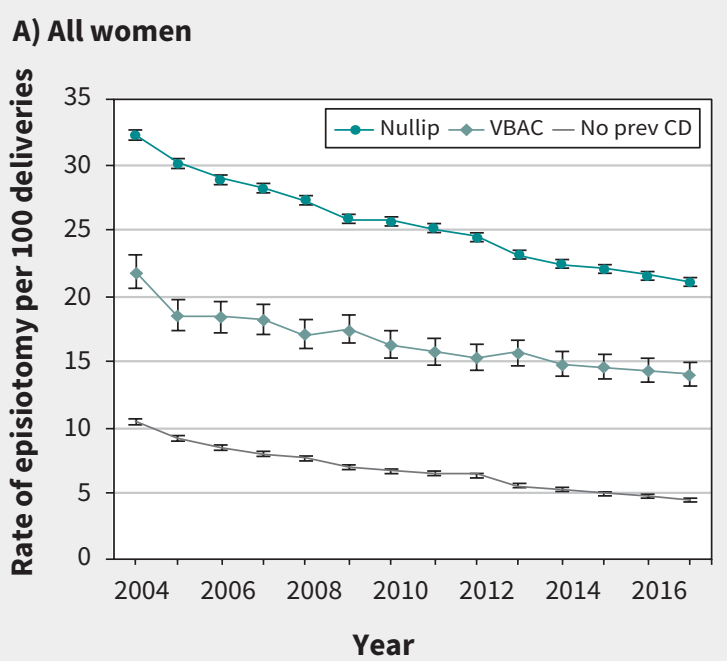

C) Parous women with no previous cesarean delivery

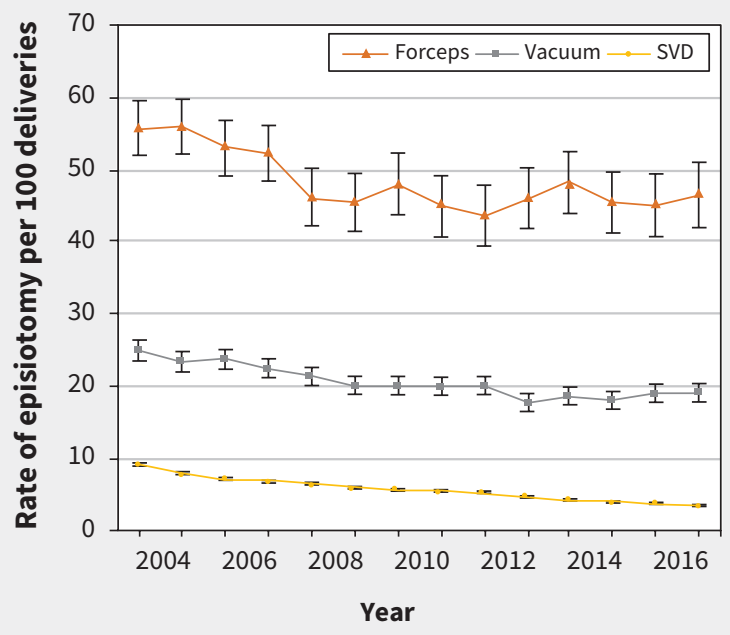

\section{B) Nulliparous women}

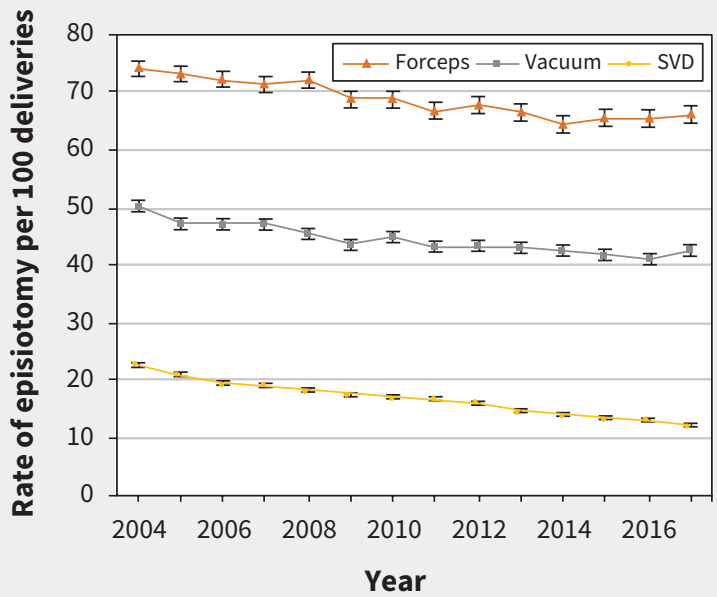

D) Women with a VBAC

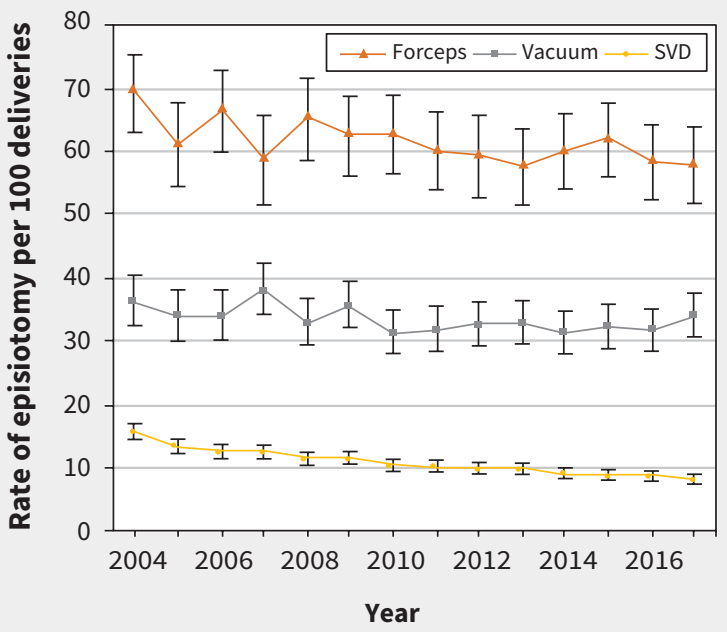

Figure 2: Temporal trends in episiotomy use stratified by parity and obstetric history among (A) all women, and stratified by mode of delivery among (B) nulliparous (nullip.) women, (C) among parous women without a previous cesarean delivery, and (D) among women with a vaginal birth after cesarean (VBAC), singleton, term deliveries, Canada, 2004-2017. $P$ value $<0.05$ for the Cochran-Armitage test for linear trend in proportions for all categories. Error bars denote $95 \%$ confidence intervals. Note: SVD = spontaneous vaginal delivery.

(adjusted RR 1.16, 95\% Cl 1.00-1.34; Table 4; Figure 3). A similar pattern was observed among deliveries with sequential instruments.

The rate of obstetric anal sphincter injury was higher among vacuum deliveries with an episiotomy in the full cohort of women, and this association was stronger in parous women without a previous cesarean delivery (adjusted RR 1.71, 95\% 1.57-1.87; Table 4). Conversely, among nulliparous women with vacuum delivery, episiotomy was associated with lower rates of obstetric anal sphincter injury (adjusted RR 0.88, 95\% Cl 0.850.91 ). No association was found among vacuum delivery in women with vaginal birth after cesarean (Figure 3).

Associations between episiotomy and obstetric anal sphincter injury in each province and territory are provided in Appendix 1,
Table S9; rates of obstetric anal sphincter injury were higher among women after spontaneous vaginal deliveries and vacuum deliveries in most regions, while obstetric anal sphincter injury rates were generally lower among women with episiotomy who delivered by forceps or use of sequential instruments. The rates of obstetric anal sphincter injury and the associations with episiotomy did not differ substantially when stratified by pelvic station (Appendix 1, Table S10). Adjusted rate differences and NNTs by mode of delivery for all groups are listed in Appendix 1, Table S11. The numbers needed to harm among spontaneous vaginal deliveries were 85, 59 and 32 in nulliparous women, parous women without cesarean delivery and women with vaginal birth after cesarean, respectively. Among nulliparous women, adjusted NNTs were 10, 60, and 9 for forceps, vacuum and sequential instruments, respectively. 
Table 3: Adjusted rate ratios expressing the association between episiotomy and obstetric anal sphincter injury among all term singleton vaginal deliveries, Canada, 2004-2017

\begin{tabular}{|cccc|}
\multicolumn{4}{c}{ OASI rate (\%) } \\
\cline { 2 - 4 } Type of delivery & $\begin{array}{c}\text { Episiotomy } \\
\text { No }\end{array}$ & $\begin{array}{c}\text { Episiotomy } \\
\text { Yes }\end{array}$ & ARR $^{\star}$ (95\% CI) \\
\hline All vaginal deliveries & 3.4 & 9.6 & $2.63(2.59-2.66)$ \\
\hline Spontaneous & 2.4 & 4.8 & $2.06(2.00-2.11)$ \\
\hline Operative & 13.2 & 15.2 & $1.19(1.16-1.21)$ \\
\hline Forceps & 24.3 & 18.1 & $0.74(0.71-0.77)$ \\
\hline Vacuum & 10.2 & 11.9 & $1.19(1.16-1.23)$ \\
\hline Sequential & 28.0 & 24.6 & $0.87(0.80-0.94)$ \\
\hline
\end{tabular}

Note: $\mathrm{ARR}=$ adjusted rate ratio, $\mathrm{CD}=$ cesarean delivery, $\mathrm{Cl}$ = confidence interval, $\mathrm{OASI}=$ obstetric anal sphincter injury.

*The reference group included deliveries without episiotomy within each respective delivery group (i.e., reference group for forceps deliveries among nulliparous women included forceps deliveries without episiotomy among nulliparous women). Models adjusted for maternal age, labour induction, prolonged second stage of labour, epidural anesthesia, infant birth weight, province and year of birth.

\section{Additional analyses}

The associations between episiotomy and obstetric anal sphincter injury were generally similar irrespective of laceration degree (third v. fourth degree; Appendix 1, Table S12), a diagnosis of fetal distress (Appendix 1, Table S13) and restriction of parous women to those with only 1 previous vaginal delivery (Appendix 1, Table S14). However, among women with vaginal birth after cesarean, restricting to those with only 1 previous cesarean delivery yielded results analogous to those in nulliparous women. The analysis by institutional delivery volume showed that the protective association between episiotomy and obstetric anal sphincter injury among forceps deliveries was stronger among nulliparous women in institutions with medium delivery volume compared with those in centres with low and high delivery volumes (Appendix 1, Table S15). Rates of obstetric anal sphincter injury among forceps and vacuum deliveries were generally higher in medium- and high-volume versus low-volume institutions. The E-values for key associations between episiotomy and obstetric anal sphincter injury in all the study strata are included in Appendix 1, Table S16. E-values for the point estimate and upper $95 \%$ confidence bound for obstetric anal sphincter injury among nulliparous women with a forceps delivery were 2.55 and 2.40 , respectively.

\section{Interpretation}

Our study shows a significant decrease in the use of episiotomy among vaginal deliveries of singleton infants at term in Canada, among both spontaneous and operative vaginal deliveries. Among spontaneous vaginal deliveries, episiotomy was associated with higher rates of obstetric anal sphincter injury, irrespective of parity and obstetric history. Conversely, the association between episiotomy and obstetric anal sphincter injury among operative vaginal deliveries varied markedly. Episiotomy decreased the risk of obstetric anal sphincter injury among operative vaginal deliveries in women delivering vaginally for the first time (i.e., among "vaginally nulliparous" women). There was a $35 \%$ to $42 \%$ reduction in the rates of obstetric anal sphincter injury in nulliparous women who had forceps deliveries with an episiotomy compared with those who did not have an episiotomy. The equivalent reduction in occurrence of obstetric anal sphincter injury among nulliparous women who had vacuum deliveries with, versus without, episiotomy was between $8 \%$ and $20 \%$. Episiotomy also had a protective effect against obstetric anal sphincter injury in women having a vaginal birth after cesarean with forceps or sequential instruments, and among women with only 1 previous cesarean delivery (i.e., vaginal nulliparous women); the same association was found in vacuum deliveries. However, among parous women without a previous cesarean delivery, forceps and vacuum delivery with episiotomy conferred up to a 2-fold higher risk of obstetric anal sphincter injury. We also found that the strength of the associations varied by hospital delivery volume, which is likely a result of variations in case mix, maternity care provider (midwife, family physician, obstetrician) and level of experience (trainee, staff).

The decline in the rate of episiotomy among spontaneous vaginal deliveries observed in our study likely reflects the impact of randomized trial evidence favouring discontinuation of routine episiotomy among spontaneous vaginal deliveries. ${ }^{22}$ The routine use of episiotomy in spontaneous vaginal deliveries is also not recommended by the Society of Obstetricians and Gynaecologists of Canada (SOGC)..$^{32}$

The 2017 Cochrane review ${ }^{22}$ that combined data from 12 randomized controlled trials examining episiotomy among vaginal deliveries included only 1 trial of women with operative vaginal delivery, and it was underpowered to detect any difference in obstetric anal sphincter injury. ${ }^{33}$ Several previous observational studies have shown a protective association between mediolateral episiotomy and obstetric anal sphincter injury among operative vaginal deliveries, similar to our findings..$^{7,19,34-41}$ However, other studies have contradicted these results ${ }^{42,43}$ or found no association. ${ }^{33,44,45}$ These latter studies failed to stratify women by obstetric history and did not examine important factors such as pelvic station, indication (e.g., fetal distress) or institutional delivery volume. ${ }^{22}$ Our analyses add to knowledge in this area by providing estimates of the association between episiotomy and obstetric anal sphincter injury while accounting for these important factors. Our results also show the pronounced decrease in the episiotomy rate among operative vaginal deliveries, suggesting that the recommendation ${ }^{32}$ to move away from routine episiotomy among spontaneous vaginal deliveries may have been overgeneralized to apply to all vaginal deliveries including operative vaginal delivery, where there may be a benefit.

Despite accumulating evidence of a protective effect of mediolateral episiotomy among operative vaginal deliveries, the SOGC guideline for operative vaginal delivery, published in 2004, recommended that routine episiotomy was not necessary for operative vaginal delivery. ${ }^{12}$ This guideline was reaffirmed in 2018 and updated in 2019 without any change in recommendations. ${ }^{46}$ Similarly, the SOGC guideline for prevention of obstetric anal 
A) Spontaneous vaginal delivery

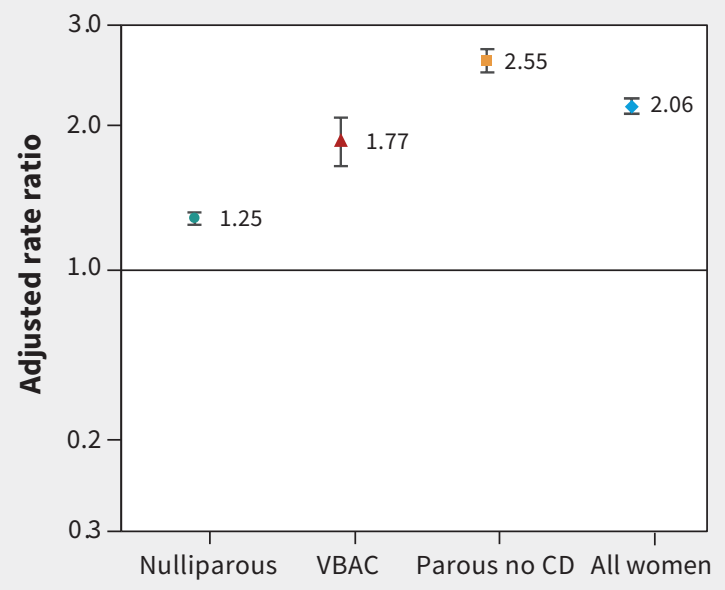

C) Vacuum delivery

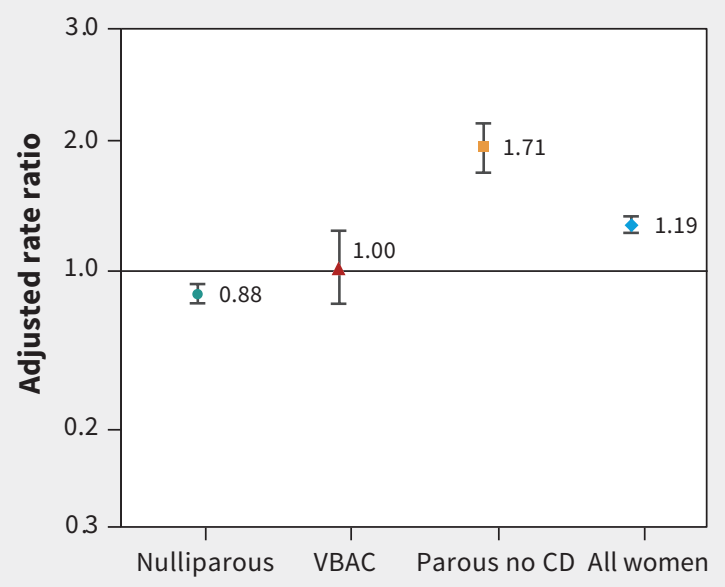

B) Forceps delivery

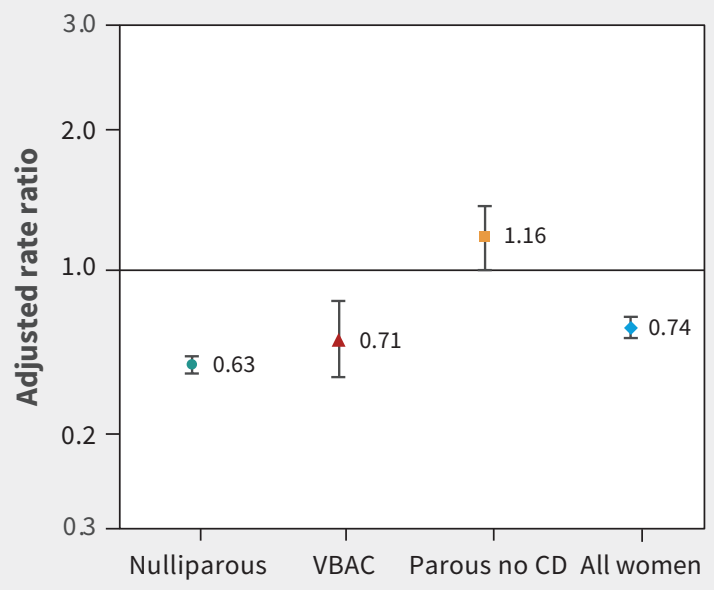

D) Sequential instruments

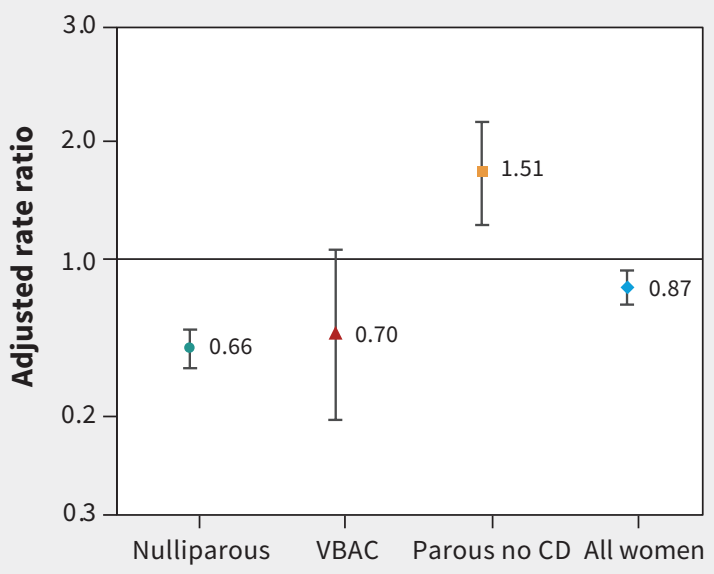

Figure 3: Adjusted rate ratios and 95\% confidence intervals expressing the association between episiotomy and obstetric anal sphincter injury among (A) all spontaneous vaginal deliveries, (B) forceps deliveries, (C) vacuum extractions, and (D) deliveries using sequential instruments. Women without an episiotomy served as the reference group for all comparisons. The $y$-axes use a logarithmic scale. Note: $C D=$ cesarean delivery, VBAC $=$ vaginal birth after cesarean.

sphincter injury recommends a policy of restricted episiotomy (i.e., only if indicated) for both spontaneous and operative vaginal delivery. ${ }^{47}$ Thus, an operative vaginal delivery, per se, is not considered to be an indication for an episiotomy. However, there is much room for interpretation on the basis of clinical judgment and the variation in the use of episiotomy among operative vaginal deliveries across Canada likely reflects this.

\section{Limitations}

Our study has several limitations. We lacked information on the type of episiotomy (midline v. mediolateral), class of thirddegree perineal laceration ( $3 \mathrm{~A}$ v. 3B), and angle of episiotomy incision. Mediolateral episiotomy accounts for more than $90 \%$ of the episiotomies that occur in Canada; ${ }^{29,30}$ however, as both techniques are likely represented in the episiotomy group, the protective effect of mediolateral episiotomy may have been attenuated by the inclusion of median procedures.

Residual confounding owing to unmeasured confounders such as previous obstetric anal sphincter injury or physician skill may have persisted despite adjustment for many risk factors; however, the sensitivity analysis using E-value methodology indicated that the observed adjusted RRs for the associations under study could be explained only by a relatively strong unmeasured confounder. The presence of such a confounder is unlikely, as in our analyses even established risk factors did not have a strong relation with both episiotomy and obstetric anal sphincter injury.

We did not use a time-series analysis as there was no material change in the recommendations regarding episiotomy use during the study period. ${ }^{32,46}$ Further, the use of a cohort design 


\section{Parous}

Nulliparous

OASI rate $(\%)$

\section{Type of delivery}

Episiotomy
Yes

$\begin{array}{cc}\text { Episiotomy } & \text { Episiotomy } \\ \text { No } & \text { Yes }\end{array}$

No previous CD

OASI rate (\%)

Episiotomy Episiotomy

All vaginal

6.7

Episiotomy Episiotomy

17.0

Vacuum

13.8

$\operatorname{ARR}^{\star}(95 \% \mathrm{Cl})$

10.9

$1.57(1.55-1.60)$

No

Yes

$\operatorname{ARR}^{\star}(95 \% \mathrm{Cl})$

$4.3 \quad 3.12(2.99-3.25)$

)

1.3

$1.25(1.21-1.28)$

1.1

$2.9 \quad 2.55(2.42-2.69)$

$0.90(0.88-0.93)$

15.7

$0.63(0.61-0.66)$

5.2

9.2

$1.83(1.71-1.96)$

$11.4 \quad 1.16(1.00-1.34)$

10.6

12.7

$0.88(0.85-0.91)$

4.4

7.6

$1.71(1.57-1.87)$

$24.4 \quad 0.66(0.60-0.72) \quad 14.4$

$18.9 \quad 1.51(1.18-1.92)$

No

Yes

$\operatorname{ARR}^{\star}(95 \% \mathrm{Cl})$

$5.7 \quad 11.6$

$2.03(1.90-2.18)$
7.2

16.5

19.1

13.7

25.9

Note: $A R R=$ adjusted rate ratio, $C D=$ cesarean delivery, $\mathrm{Cl}=$ confidence interval, $\mathrm{OASI}=$ obstetric anal sphincter injury, $\mathrm{OVD}=$ operative vaginal delivery, $\mathrm{SVD}=$ spontaneous vaginal delivery, $\mathrm{VBAC}=$ vaginal birth after cesarean.

*The reference group included deliveries without episiotomy within each respective delivery group; i.e., reference group for forceps deliveries among nulliparous women included forceps deliveries without episiotomy among nulliparous women. Models adjusted for maternal age, labour induction, prolonged second stage of labour, epidural anesthesia, infant birth weight, province and year of birth.

allowed for the adjustment of individual-level confounders, thereby reducing the potential for residual confounding (which is more likely with ecological time-series analyses). Lastly, we did not include any potential time-varying covariates in our statistical models. However, we included the year of delivery using indicator variables and the associations presented were therefore adjusted for changes over time.

\section{Conclusion}

Episiotomy use has declined in Canada among spontaneous and operative vaginal deliveries. Given the opposite associations between episiotomy and obstetric anal sphincter injury in women after spontaneous and operative vaginal delivery, generalizing the episiotomy guidelines for spontaneous vaginal delivery to women with operative vaginal delivery may cause harm, particularly in nulliparous women and women who have a vaginal birth after cesarean delivery. In such women, more liberal use of an adequate mediolateral episiotomy with operative vaginal delivery, especially forceps, may be warranted, given the protective association between episiotomy and obstetric anal sphincter injury.

\section{References}

1. Handa VL, Danielsen BH, Gilbert WM. Obstetric anal sphincter lacerations. Obstet Gynecol 2001;98:225-30.

2. Sultan AH, Thakar R. Third and fourth degree tears. In: Sultan AH, Thakar R, Fenner DE, editors. Perineal and anal sphincter trauma. 1st ed. London (UK): Springer-Verlag; 2009:33-51.

3. Muraca GM, Lisonkova S, Skoll A, et al. Ecological association between operative vaginal delivery and obstetric and birth trauma. CMAJ 2018;190:E734-41.

4. Ekéus C, Nilsson E, Gottvall K. Increasing incidence of anal sphincter tears among primiparas in Sweden: a population-based register study. Acta Obstet Gynecol Scand 2008;87:564-73.

5. Prager M, Andersson KL, Stephansson O, et al. The incidence of obstetric anal sphincter rupture in primiparous women: a comparison between two European delivery settings. Acta Obstet Gynecol Scand 2008;87:209-15.
6. Laine K, Gissler M, Pirhonen J. Changing incidence of anal sphincter tears in four Nordic countries through the last decades. Eur J Obstet Gynecol Reprod Biol 2009;146:71-5.

7. Gurol-Urganci I, Cromwell DA, Edozien LC, et al. Third- and fourth-degree perineal tears among primiparous women in England between 2000 and 2012: time trends and risk factors. BJOG 2013;120:1516-25.

8. Ismail SI, Puyk B. The rise of obstetric anal sphincter injuries (OASIS): 11-year trend analysis using Patient Episode Database for Wales (PEDW) data. J Obstet Gynaecol 2014;34:495-8.

9. Dahlen H, Priddis H, Schmied V, et al. Trends and risk factors for severe perineal trauma during childbirth in New South Wales between 2000 and 2008: a population-based data study. BMJ Open 2013;3. pii: e002824.

10. Benchmarking Canada's health care systems: international comparisons historical data. Ottawa: Canadian Institute for Health Information (CIHI); 2013. Available: www.cihi.ca /sites/default/files/document/oecd-interactive-tool -historical-data-tables-en-web.zip (accessed 2019 Jan. 16).

11. Your health system. Ottawa: Canadian Institute for Health Information (ClHI). Available: https://yourhealthsystem.cihi.ca/hsp/indepth? lang=en\#/indicator/ 048/3/C9056/N4IgKgTgpgdgJgeQG5QmAlgWygYQC4QA2IAXKAM5QAepIAYiAL 4AOIAQgIYQDiEHADgAt8RUhWq0GjRkAAA (accessed 2019 Jan. 16).

12. Cargill YM, MacKinnon CJ. No. 148-Guidelines for operative vaginal birth. J Obstet Gynaecol Can 2018;40:e74-80.

13. Muraca GM, Sabr Y, Brant R, et al. Temporal and regional variations in operative vaginal delivery in Canada by pelvic station, 2004-2012. J Obstet Gynaecol Can 2016;38:627-35.

14. European perinatal health report. Core indicators of the health and care of pregnant women and babies in Europe in 2015. Euro-Peristat Project; 2018. Available: www.europeristat.com (accessed 2019 Jan. 16).

15. National perinatal data collection. Perinatal data visualisations: method of delivery. Canberra (AU): Australian Institute of Health and Welfare; updated 2019 June 27. Available: www.aihw.gov.au/reports/mothers-babies/perinatal-data -visualisations/contents/data-visualisations (accessed 2019 Jan. 17).

16. Martin JA, Hamilton BE, Osterman MJK, et al. Births: final data for 2015. Natl Vital Stat Rep 2017;66:1-70.

17. Caughey AB, Cahill AG, Guise JM, et al. Safe prevention of the primary cesarean delivery. Am J Obstet Gynecol 2014;210:179-93.

18. Baumann P, Hammoud AO, McNeeley SG, et al. Factors associated with anal sphincter laceration in 40923 primiparous women. Int Urogynecol J Pelvic Floor Dysfunct 2007;18:985-90.

19. Baghestan E, Irgens LM, Bordahl PE, et al. Trends in risk factors for obstetric anal sphincter injuries in Norway. Obstet Gynecol 2010;116:25-34.

20. Richter HE, Brumfield CG, Cliver SP, et al. Risk factors associated with anal sphincter tear: a comparison of primiparous patients, vaginal births after cesarean deliveries, and patients with previous vaginal delivery. Am J Obstet Gynecol 2002;187:1194-8. 
21. Cunningham FG, Leveno KJ, Bloom SL, et al. Williams obstetrics. 25th ed. New York: McGraw-Hill Medical; 2018.

22. Jiang H, Qian X, Carroli G, et al. Selective versus routine use of episiotomy for vaginal birth. Cochrane Database Syst Rev 2017;(2):CD000081.

23. Intrapartum care for a positive childbirth experience. Geneva: World Health Organization; 2018.

24. Wen SW, Liu S, Marcoux S, et al. Uses and limitations of routine hospital admission/ separation records for perinatal surveillance. Chronic Dis Can 1997;18:113-9.

25. International statistical classification of diseases and related health problems: tenth revision. Ottawa: Canadian Institute for Health Information; 2015. Available: https://secure.cihi.ca/estore/productSeries.htm? pc=PCC189 (accessed 2019 Jan. 17).

26. Canadian classification of health interventions. Ottawa: Canadian Institute for Health Information; 2015. Available: https://secure.cihi.ca/estore/productSeries. htm?pc=PCC189 (accessed 2019 Jan. 17).

27. Joseph KS, Fahey J. Validation of perinatal data in the Discharge Abstract Database of the Canadian Institute for Health Information. Chronic Dis Can 2009;29:96-100.

28. Data quality study of the 2015-2016 Discharge Abstract Database: a focus on hospital harm. Ottawa: Ottawa: Canadian Institute for Health Information; 2016.

29. Menzies R, Leung M, Chandrasekaran N, et al. Episiotomy technique and management of anal sphincter tears - a survey of clinical practice and education. J Obstet Gynaecol Can 2016;38:1091-99.e2.

30. Muraca GM, Skoll A, Lisonkova S, et al. Perinatal and maternal morbidity and mortality among term singletons following midcavity operative vaginal delivery versus caesarean delivery. BJOG 2018;125:693-702.

31. VanderWeele TJ, Ding P. Sensitivity analysis in observational research: introducing the e-value. Ann Intern Med 2017;167:268-74.

32. Lee L, Dy J, Azzam H. Management of spontaneous labour at term in healthy women. J Obstet Gynaecol Can 2017;39:222.

33. Murphy DJ, Macleod M, Bahl R, et al. A randomised controlled trial of routine versus restrictive use of episiotomy at operative vaginal delivery: a multicentre pilot study. BJOG 2008;115:1695-702.

34. de Leeuw JW, de Wit C, Kuijken JP, et al. Mediolateral episiotomy reduces the risk for anal sphincter injury during operative vaginal delivery. BJOG 2008;115:104-8.
35. Revicky V, Nirmal D, Mukhopadhyay S, et al. Could a mediolateral episiotomy prevent obstetric anal sphincter injury? Eur J Obstet Gynecol Reprod Biol 2010;150:142-6.

36. Räisänen S, Vehviläinen-Julkunen K, Cartwright R, et al. Vacuum-assisted deliveries and the risk of obstetric anal sphincter injuries - a retrospective register-based study in Finland. BJOG 2012;119:1370-8.

37. de Vogel J, Van Der Leeuw-Van Beek A, Gietelink D, et al. The effect of a medio lateral episiotomy during operative vaginal delivery on the risk of developing obstetrical anal sphincter injuries. Am J Obstet Gynecol 2012;206:404.e1-5.

38. Jangö H, Langhoff-Roos J, Rosthøj S, et al. Modifiable risk factors of obstetric anal sphincter injury in primiparous women: a population-based cohort study. Am J Obstet Gynecol 2014;210:59.e1-6.

39. Sagi-Dain L, Sagi S. Morbidity associated with episiotomy in vacuum delivery: a systematic review and meta-analysis. BJOG 2015;122:1073-81.

40. van Bavel J, Hukkelhoven CW, de Vries $C$, et al. The effectiveness of mediolateral episiotomy in preventing obstetric anal sphincter injuries during operative vaginal delivery: a ten-year analysis of a national registry. Int Urogynecol J 2018;29:407-13.

41. Boujenah J, Tigaizin A, Fermaut M, et al. Is episiotomy worthwhile to prevent obstetric anal sphincter injury during operative vaginal delivery in nulliparous women? Eur J Obstet Gynecol Reprod Biol 2019;232:60-4.

42. Steed $\mathrm{H}$, Corbett $\mathrm{T}$, Mayes $\mathrm{D}$. The value of routine episiotomy in forceps deliveries. JOGC 2000;22:583-6.

43. Youssef R, Ramalingam U, Macleod M, et al. Cohort study of maternal and neonatal morbidity in relation to use of episiotomy at instrumental vaginal delivery. BJOG 2005;112:941-5.

44. Hudelist G, Gelle'n J, Singer C, et al. Factors predicting severe perineal trauma during childbirth: role of forceps delivery routinely combined with mediolateral episiotomy. Am J Obstet Gynecol 2005;192:875-81.

45. Macleod M, Strachan B, Bahl R, et al. A prospective cohort study of maternal and neonatal morbidity in relation to use of episiotomy at operative vaginal delivery. BJOG 2008;115:1688-94.

46. Hobson S, Cassell K, Windrim R, et al. No. 381 - assisted vaginal birth. J Obstet Gynaecol Can 2019;41:870-82.

47. Harvey MA, Pierce M, Walter JE, et al. Obstetrical anal sphincter injuries (OASIS): prevention, recognition, and repair. J Obstet Gynaecol Can 2015;37:1131-48.

\section{Competing interests: None declared.}

This article has been peer reviewed.

Affiliations: Clinical Epidemiology Unit, Department of Medicine (Muraca, Stephansson, Razaz), Solna, Karolinska University Hospital, Karolinska Institutet, Stockholm, Sweden; Department of Obstetrics \& Gynaecology (Muraca, Sabr, Lisonkova, Skoll, Cundiff, Joseph), University of British Columbia, Vancouver, BC; Maternal, Child and Youth Health Division (Liu), Centre for Surveillance and Applied Research, Public Health Agency of Canada, Ottawa, Ont.; Department of Obstetrics and Gynaecology (Sabr), King Saud University, Riyadh, Saudi Arabia; School of Population and Public Health (Lisonkova, Joseph); Department of Statistics (Brant), University of British Columbia, Vancouver, BC; Department of Women's and Children's Health, Division of Obstetrics and Gynaecology (Stephansson), Karolinska Institutet, Stockholm, Sweden

Contributors: Giulia Muraca and K.S. Joseph proposed the study concept and design, and were assisted by Shiliang Liu, Sarka Lisonkova, Amanda Skoll, Rollin Brant, Yasser Sabr, Geoffrey Cundiff, Olof Stephansson, and Neda Razaz. Giulia Muraca and Shiliang Liu acquired the data. Giulia Muraca and Shiliang Liu conducted the analyses. Shiliang Liu, Sarka Lisonkova, Amanda Skoll, Rollin Brant, Yasser Sabr, Geoffrey Cundiff, Olof Stephansson, Neda Razaz and K.S. Joseph reviewed the preliminary and final analyses. Giulia Muraca drafted the manuscript. All of the authors reviewed the manuscript critically for important intellectual content, gave final approval of the version to be published and agreed to be accountable for all aspects of the work.

Funding: Giulia Muraca and Neda Razaz are the recipients of the Canadian Institutes of Health Research (CIHR) Postdoctoral Fellowship; K.S. Joseph is supported by the BC Children's Hospital Research Institute. This study was funded by a CIHR grant (PER-150902). Sarka Lisonkova is supported by a Scholar Award from the Michael Smith Foundation for Health Research. Olof Stephansson is sup- ported by the Swedish Research council (5232013-2429), the Swedish Research Council for Health, Working Life and Welfare (201500251), Stockholm Country Council, and the Strategic Research Programme in Epidemiology at Karolinska Institutet.

Disclaimer: Data for this study were provided by the Canadian Institute for Health Information (ClHI). However, the analyses, conclusions, and opinions expressed herein are those of the authors and not those of $\mathrm{CIHI}$.

Data sharing: These data were acquired from the Canadian Institute for Health Information $(\mathrm{ClHI})$. Access to these data are available to researchers, health managers and decision-makers via a formal data request process administered by $\mathrm{ClHI}$. More information on the data holdings and the request process is available at www.cihi.ca/en/access -data-and-reports/make-a-data-request.

Accepted: Sept. 16, 2019

Correspondence to: Giulia Muraca, giulia.muraca@ki.se 